\title{
The Response of Jaundiced and Non-Jaundiced Weanling Rats to Thirsting
}

\author{
G.B. ODELL ${ }^{[26]}$ \\ Department of Pediatrics, Johns Hopkins University School of Medicine, \\ and the Harriet Lane Service of the Johns Hopkins Children's Medical and Surgical Center, \\ Baltimore, Maryland, USA
}

\begin{abstract}
Extract
Litter-mate homozygous and heterozygous weanling rats of the Gunn strain were thirsted and fasted for 24 hours. The response of the animals to thirsting was compared by analysis of solute content of serum and composition of fluid in the renal medullae. The results are given in tables I and II. When the mean values for weight loss and serum solute concentrations were compared, it was found that the jaundiced rats were able to conserve body water as well as the non-jaundiced rats and to generate equally high concentrations of total solute in the tissue water of the renal medulla. Only two of the twelve jaundiced animals showed evidence of failure to develop the expected hypertonicity of the medullary tissue water. This failure was qualitatively similar to that found in adult jaundiced rats. Despite the presence of higher concentrations of bilirubin in serum, the medullary bilirubin content of the jaundiced weanling rat was only $5 \%$ of the concentration found in adult animals. The sodium and urea concentrations in the renal medullary fluid were correlated $(p<0.001)$ in the homozygous jaundiced rats (table IV and fig.1). A similar correlation was not found in the non-jaundiced heterozygous animals. This finding suggests that the normal rat kidney has at least two mechanisms for renal transport of urea, one of which is sodium dependent and the other sodium independent and that the latter mechanism is inoperative in the jaundiced weanling rat.
\end{abstract}

\section{Speculation}

In vitro studies of bilirubin have previously suggested that toxicity is exerted by its surface activity on mitochondrial membranes. The examination of renal function in the intact jaundiced animal has revealed the possibility that tubular transport systems for urea and sodium are impaired in the presence of high concentrations of bilirubin in the renal medulla. These transport systems involve the maintenance of concentration gradients of sodium and urea across tubular epithelium. Bilirubin, through its surface activity, could impair the selective permeability of the membranes involved in urea and sodium transport within the renal medulla.

\section{Introduction}

The homozygous (jj) Gunn strain rat has a life-long unconjugated hyperbilirubinemia which develops a few days after birth [11]. The hyperbilirubinemia is a result of a deficiency in the hepatic microsomal enzyme, glucuronyl transferase, which catalyzes the conjugation of bilirubin prior to hepatic excretion as the diglucuronide ester $[3,15,21]$.

Recently, it was reported that the adult homozygous 
(jj) rat, in comparison with the non-jaundiced heterozygous (jJ) animal, is unable to form concentrated urine and develops hyperosmolality of the extracellular fluids when thirsted [18]. The failure in water conservation has been explained by the presence of greater urinary water and sodium losses in the distal tubule associated with lower tissue osmolality of the inner renal medulla in comparison with conditions found in the heterozygous animals. Regional analysis of the kidney for bilirubin revealed a concentration of bilirubin in the inner medulla that was 100 -fold greater than that in the cortex. These observations were interpreted to indicate that bilirubin may interfere with the reabsorption and counter-current recirculation of sodium and urea in the loop of Henle and thereby limit tubular reabsorption of solute-free water from the collecting ducts.

In order to ascertain whether the concentrating defect and the hyperbilirubinemia were separate but closely associated genetic defects or whether the renal lesion was a consequence of bilirubin accumulation, the response of young animals to thirsting was studied.

\section{Materials and Methods}

Twelve homozygous and 12 heterozygous litter-mates from four litters were separated from their mothers at 19-26 days of life and were thirsted and fasted for 24 hours.

The weights of the animals were determined just before and at the completion of the 24-hour thirst. The animals were anesthetized with pentobarbital, $3 \mathrm{mg} / 100 \mathrm{~g}$ given by intraperitoneal injection, and a midabdominal incision was made. The abdominal aorta was transected and blood was collected in capillary tubes directly from the bleeding site. Both kidneys were removed subsequently and shelled from their capsules. Each kidney was hemisectioned; the papilla, including the inner medulla, was excised and its wet weight measured on preweighed aluminum planchets with a gram electric balance (Cahn Instrument Co., Paramount, California). One medulla was dried for 24 hours at $90^{\circ}$ and reweighed to obtain the water content. The medulla from the other kidney was quantitatively transferred to a glass homogenizer with $1 \mathrm{ml}$ of distilled water. After the sample was homogenized, aliquots were analyzed for ammonia, urea, sodium and potassium contents. The capillary blood samples were centrifuged and the supernatant serum analyzed for concentrations for total protein, bilirubin, urea, sodium and potassium. The analytic methods have been previously reported [18].

After a thirsting period of 24 hours, the bilirubin content of the inner medulla of the kidney was deter- mined in six additional homozygous weanling rats by homogenizing both of the excised medullae in $1 \mathrm{ml}$ of $0.01 \mathrm{~N} \mathrm{HCl}$ and $1 \mathrm{ml}$ of chloroform. Following centrifugation, the bilirubin analysis of the chloroform layer was performed by direct spectrophotometric analysis [18].

These values were compared with the analyses of medullary bilirubin concentrations in 11 homozygous adult rats which had not been subjected to thirsting before the analyses.

\section{Results}

The values for the changes in weight and serum analyses of the animals are recorded in table $\mathrm{I}$. There were no significant differences between any of the mean values for the homozygous and heterozygous animals even though the mean weight loss was greater in the jaundiced animals.

The results of the analyses of the inner medulla of the kidneys are itemized in table II. Although the mean values for concentrations of sodium and urea and the calculated tissue osmolalities were lower in the homozygous animals, these differences were not statistically significant. Animals $\mathrm{jj} 10$ and $\mathrm{jj} 13$, however, did exhibit a deficiency of water conservation in that they incurred the greatest weight losses and had the highest concentrations of sodium in serum. Despite these indications of dehydration, the tissue osmolalities of their renal medullae were the lowest in the entire group, and involved reductions in the concentrations of sodium and urea.

The bilirubin contents of the inner medullae of the kidneys in the thirsted weanling rats are given in table

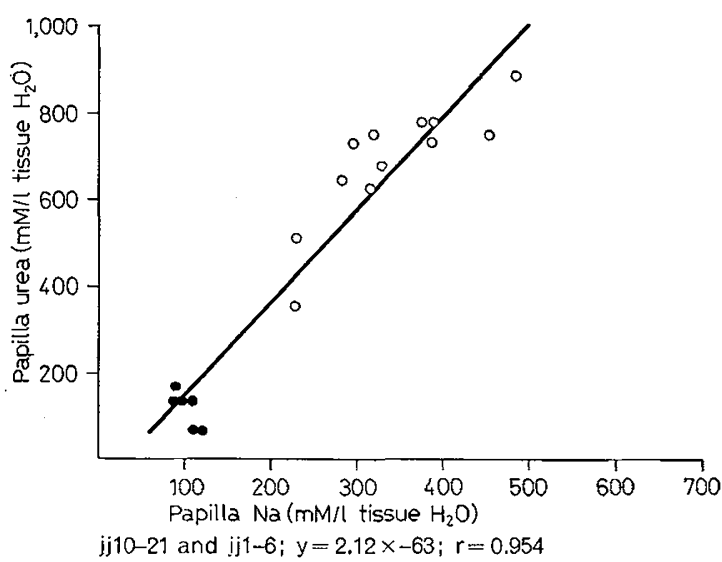

Fig. 1. The simultaneous relation between the papillary urea and sodium concentrations in weanling and adult homozygous jaundiced rats. $\odot$, represents the weanling rats jj10-21 of table II. $\bullet$, represents the adult animals jj1-6 previously studied [18]. 
The response of jaundiced and non-jaundiced weanling rats to thirsting

Table $I$. Weight changes and chemical values in serum of thirsted homozygous animals

\begin{tabular}{|c|c|c|c|c|c|c|c|c|c|}
\hline \multirow[t]{3}{*}{ Animal } & \multirow[t]{2}{*}{ Age } & \multirow[t]{3}{*}{ Sex } & \multirow{2}{*}{$\begin{array}{l}\text { Initial } \\
\text { weight }\end{array}$} & \multirow{2}{*}{$\begin{array}{l}\text { Weight } \\
\text { loss }\end{array}$} & \multicolumn{3}{|c|}{ Concentrations in serum } & \multirow{3}{*}{$\begin{array}{l}\text { Total } \\
\text { Protein } \\
\mathrm{g} / 100 \mathrm{~m}\end{array}$} & \multirow{3}{*}{$\begin{array}{l}\text { Bilirubin } \\
\mathrm{mg} / 100 \mathrm{ml}\end{array}$} \\
\hline & & & & & $\mathrm{Na}$ & $\mathbf{K}$ & Urea & & \\
\hline & Days & & $\mathrm{g}$ & $\%$ & \multicolumn{3}{|c|}{$\mathrm{mM} / \mathrm{l}$} & & \\
\hline $\mathrm{jj} 10$ & 22 & $\sigma$ & 42.2 & 21.1 & 146.0 & 5.0 & 7.9 & & 22.4 \\
\hline jj11 & 22 & $\sigma^{\pi}$ & 38.7 & 19.7 & 141.2 & 4.6 & 7.3 & & 16.8 \\
\hline jj12 & 24 & 우 & 34.0 & 21.2 & 148.2 & 4.2 & 8.2 & 5.1 & 13.6 \\
\hline $\mathrm{jj} 13$ & 24 & $\hat{0}$ & 48.5 & 23.1 & 153.6 & 5.6 & 8.1 & 6.0 & 16.8 \\
\hline $\mathrm{jj} 14$ & 20 & $\sigma^{\pi}$ & 31.6 & 14.5 & 141.0 & 4.2 & 6.4 & 4.5 & 14.4 \\
\hline jj15 & 20 & $\delta$ & 32.3 & 13.3 & 139.0 & 4.6 & 5.9 & 4.6 & 17.0 \\
\hline jj16 & 22 & 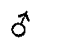 & 39.8 & 12.6 & 144.2 & 4.6 & 4.6 & 5.3 & 36.0 \\
\hline $\mathrm{jj} 17$ & 22 & 우 & 40.2 & 10.0 & 141.4 & 5.4 & 3.9 & 4.9 & 13.6 \\
\hline jj18 & 25 & 우 & 44.5 & 16.9 & 139.0 & 4.8 & 8.5 & 5.1 & 16.8 \\
\hline $\mathrm{jj} 19$ & 25 & 우 & 46.8 & 16.5 & 137.8 & 5.4 & 7.9 & 5.5 & 12.8 \\
\hline $\mathrm{jj} 20$ & 27 & 우 & 49.6 & 17.8 & 142.0 & 4.4 & 11.8 & 5.6 & 15.6 \\
\hline $\mathrm{jj} 21$ & 27 & 우 & $56: 3$ & 14.7 & 139.0 & 5.4 & 8.4 & 5.2 & 16.8 \\
\hline Mean & & & 42 & 16.7 & 142.6 & 4.9 & 7.4 & 5.2 & 17.7 \\
\hline $\mathrm{SD} \pm$ & & & 7.5 & 4.0 & 4.6 & 0.5 & 2.1 & 0.5 & 6.3 \\
\hline jJ10 & 22 & 우 & 36.6 & 16.7 & 141.6 & 6.2 & 9.4 & & \\
\hline $\mathrm{jJ} 11$ & 22 & $\pi$ & 47.7 & 17.7 & 145.4 & 5.0 & 8.4 & & \\
\hline jJ12 & 24 & $\widehat{0}$ & 49.0 & 16.3 & 143.6 & 5.6 & 6.4 & 4.9 & \\
\hline jJ13 & 24 & ㅇ & 45.3 & 17.2 & 146.8 & 4.9 & 6.9 & 4.9 & \\
\hline jJ14 & 20 & $\sigma^{\pi}$ & 31.2 & 14.1 & 142.5 & & 7.4 & & \\
\hline jJ15 & 20 & 우 & 30.0 & 13.7 & 131.0 & & 7.6 & & \\
\hline jJ16 & 22 & $\pi$ & 45.4 & 10.8 & 140.4 & 5.0 & 4.5 & 5.1 & \\
\hline $\mathrm{jJ} 17$ & 22 & $\hat{\sigma}$ & 41.2 & 11.2 & 144.0 & 5.2 & 4.3 & 5.2 & \\
\hline jJ18 & 25 & 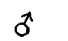 & 49.3 & 14.8 & 139.8 & 5.6 & 10.0 & 5.4 & . \\
\hline jJ19 & 25 & 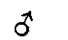 & 51.4 & 16.9 & 137.6 & 4.6 & 6.4 & 5.1 & \\
\hline jJ20 & 27 & $\widehat{0}$ & 56.8 & 15.1 & 140.2 & 4.6 & 10.9 & 5.0 & \\
\hline jJ21 & 27 & 우 & 59.9 & 11.5 & 144.0 & 5.2 & 7.0 & 5.2 & \\
\hline Mean & & & 44.7 & 14.6 & 141.2 & 5.2 & 7.4 & 5.1 & \\
\hline $\mathrm{SD} \pm$ & & & 9.3 & 2.4 & 4.2 & 0.5 & 2.0 & 0.2 & \\
\hline
\end{tabular}

III and are compared with the values found in adult animals. It is evident that there was much less bilirubin within the medullary portions of the kidney in weanling rats despite higher concentrations of bilirubin in serum.

In table IV are listed the derived statistical correlations for the major medullary solutes. There were highly significant correlations between the total osmolality and the concentrations of sodium and urea within the medulla in both groups of animals. When the sodium and urea concentrations were compared with one another, however, differences were found between the homozygous ( $\mathrm{jj}$ ) and heterozygous animals.

The concentrations of sodium and urea varied independently of one another in the heterozygous animals, whereas the concentrations of these two medullary solutes were closely associated with one another in the homozygous animals. Recalculation of the correlation by eliminating animals $\mathrm{jj} 10$ and $\mathrm{jj} 13$ results in an even higher correlation $(r=0.98, p<0.001)$; thus the existence of the correlation was not dependent upon just these two animals.

\section{Discussion}

The analyses of the solutes of the inner medulla in the homozygous weanling rat demonstrated that their medullary structures could generate and maintain the hypertonicity of the papillary fluid comparable to the values of non-jaundiced heterozygous animals. Since there is general agreement that, in the presence of antidiuretic hormone, osmotic equilibrium exists between the tubular fluid of the collecting duct and the adjacent interstitial fluid of the papilla $[1,8,23,24]$, the present results suggest that the jaundiced weanling rat could concentrate urine as well as could its heterozygous litter-mate. It therefore seems reașonable to 
Table II. Composition of inner medulla of the kidneys

\begin{tabular}{|c|c|c|c|c|c|c|c|c|}
\hline \multirow[t]{3}{*}{ Animal } & \multirow{3}{*}{$\begin{array}{l}\text { Sample } \\
\text { weight } \\
\mathrm{mg}\end{array}$} & \multirow{3}{*}{$\begin{array}{l}\text { Water } \\
\%\end{array}$} & \multirow{3}{*}{$\begin{array}{l}\text { Content } \\
\mu \mathrm{l}\end{array}$} & \multicolumn{4}{|c|}{ Solute concentrations } & \multirow{3}{*}{$\begin{array}{l}\text { Osmolality }^{1} \\
\mathrm{mOsm} / \mathrm{kg}\end{array}$} \\
\hline & & & & $\overline{\mathrm{Na}}$ & $\mathrm{K}$ & $\mathrm{NH}_{4}$ & $\overline{\text { Urea }}$ & \\
\hline & & & & \multicolumn{4}{|c|}{$\mathrm{mM} / \mathrm{l}$ tissue water } & \\
\hline jj10 & 4.16 & 82.2 & 3.42 & 230 & 73.9 & 17.0 & 510 & 1152 \\
\hline $\mathrm{jj} 11$ & 4.67 & 79.0 & 3.68 & 329 & 65.2 & 13.6 & 679 & 1495 \\
\hline jj12 & 5.16 & 76.5 & 3.95 & 318 & 88.0 & 30.7 & 626 & 1500 \\
\hline jj13 & 4.54 & 82.0 & 3.71 & 229 & 73.4 & 18.3 & 357 & 991 \\
\hline $\mathrm{jj} 14$ & 2.80 & 78.0 & 2.18 & 389 & 83.0 & 21.3 & 772 & 1758 \\
\hline jj15 & 3.60 & 80.0 & 2.88 & 382 & 79.8 & 18.6 & 775 & 1737 \\
\hline jj16 & 3.76 & 82.0 & 3.10 & 297 & 67.6 & 19.6 & 729 & 1499 \\
\hline jj17 & 5.67 & 80.0 & 4.53 & 320 & 63.9 & 17.3 & 746 & 1548 \\
\hline $\mathrm{jj} 18$ & 7.46 & 76.0 & 5.66 & 282 & 74.0 & 24.6 & 641 & 1403 \\
\hline jj19 & 6.11 & 76.5 & 4.67 & 392 & 75.0 & 29.1 & 735 & 1727 \\
\hline $\mathrm{jj} 20$ & 4.31 & 76.4 & 3.29 & 456 & 85.1 & 28.2 & 743 & 1881 \\
\hline $\mathrm{jj} 21$ & 4.72 & 76.4 & 3.60 & 486 & 75.0 & 29.7 & 879 & 2061 \\
\hline Mean & 4.75 & 78.7 & 3.73 & 343 & 75.2 & 22.3 & 682 & 1563 \\
\hline $\mathrm{SD}_{ \pm}$ & 1.24 & 2.4 & 0.91 & 81 & 7.6 & 5.9 & 138 & 298 \\
\hline $\mathrm{jJ} 10$ & 4.78 & 77.8 & 3.72 & 227 & 67.2 & 17.3 & 699 & 1321 \\
\hline jJ11 & 4.42 & 78.8 & 3.49 & 352 & 66.0 & 22.4 & 904 & 1784 \\
\hline jJ12 & 4.63 & 76.0 & 3.52 & 415 & 99.0 & 22.3 & 790 & 1862 \\
\hline $\mathrm{jJ} 13$ & 4.14 & 75.2 & 3.11 & 424 & 106.0 & 23.0 & 885 & 1991 \\
\hline jJ14 & 3.46 & 80.3 & 2.76 & 351 & 61.6 & 15.5 & 536 & 1394 \\
\hline jJ15 & 4.81 & 80.6 & 3.90 & 259 & 82.1 & 15.6 & 652 & 1366 \\
\hline jJ16 & 3.73 & 79.0 & 2.94 & 381 & 74.8 & 18.1 & 754 & 1702 \\
\hline jJ17 & 5.20 & 79.0 & 4.08 & 275 & 56.5 & 17.6 & 765 & 1465 \\
\hline $\mathrm{jJ} 18$ & 6.30 & 76.2 & 4.80 & 334 & 79.1 & 23.8 & 725 & 1599 \\
\hline jJ19 & 6.18 & 77.4 & 4.78 & 343 & 62.8 & 20.9 & 662 & 1516 \\
\hline jJ20 & 6.71 & 79.2 & 5.32 & 410 & 82.2 & 23.5 & 714 & 1746 \\
\hline $\mathrm{jJ} 21$ & 3.90 & 78.6 & 3.06 & 451 & 78.4 & 21.0 & 749 & 1849 \\
\hline Mean & 4.85 & 78.1 & 3.79 & 351 & 76.2 & 20.1 & 736 & 1632 \\
\hline $\mathrm{SD} \pm$ & 1.06 & 1.7 & 0.82 & 70 & 15.0 & 3.1 & 100 & 221 \\
\hline
\end{tabular}

${ }^{1}$ Calculated osmolality $=\left[\mathrm{Na}+\mathrm{K}+\mathrm{NH}_{4}\right] \times 2+$ urea.

Table III. Bilirubin contents of inner renal medulla

\begin{tabular}{lcl}
\hline & \multicolumn{2}{c}{ Bilirubin } \\
\cline { 2 - 3 } & $\begin{array}{l}\text { Serum } \\
\mathrm{mg} / 100 \mathrm{ml}\end{array}$ & $\begin{array}{l}\text { Medulla } \\
\mu \mathrm{g} / \mathrm{mg} \\
\text { wet weight }\end{array}$ \\
\hline Adult jj $(\mathrm{n}=11)$ & $9.4 \pm 2.3$ & $1.39 \pm 0.53$ \\
\hline Weanling jj $(\mathrm{n}=6)$ & $12.7 \pm 1.7$ & $0.05 \pm 0.02$ \\
\hline
\end{tabular}

Table IV. Correlations in medullary solute composition

\begin{tabular}{llll}
\hline $\mathrm{jj}(\mathrm{n}=12)$ & T. osm. vs urea & $\mathrm{r}=0.935$ & $\mathrm{p}<0.001$ \\
& T. osm. vs $\mathrm{Na}$ & $\mathrm{r}=0.971$ & $\mathrm{p}<0.001$ \\
& Urea vs $\mathrm{Na}$ & $\mathrm{r}=0.833$ & $\mathrm{p}<0.001$ \\
$\mathrm{jJ}(\mathrm{n}=12)$ & T. osm. vs urea & $\mathrm{r}=0.739$ & $\mathrm{p}<0.01$ \\
& T. osm. vs $\mathrm{Na}$ & $\mathrm{r}=0.876$ & $\mathrm{p}<0.001$ \\
& Urea vs $\mathrm{Na}$ & $\mathrm{r}=0.338$ & $\mathrm{p}>0.1$ \\
\hline
\end{tabular}

conclude that the impairment in urine concentration uniformly seen in adult jaundiced rats does not exist as a defect operative from birth. Of relevance was the observation that the bilirubin content of the inner medulla was only $5 \%$ of that found in the older jaundiced animals despite higher concentrations of circulating bilirubin in the young rats. The bilirubin concentration in the medulla, however, was still five-fold greater than the values previously found in the cortex [18]. Only two of the 12 jaundiced animals (jj10 and jj13], demonstrated subnormal medullary tonicity despite excessive weight losses and relative hypernatremia in response to thirsting. In this respect they exhibited qualitatively the same failure of water conservation as that of the adult animals. Unfortunately, the bilirubin content of their medullae was not simultaneously analyzed with the other solutes and could conceivably have been considerably greater than that found in the few 
animals studied. Although there is insufficient evidence to justify a definitive conclusion, it seems likely that the progressive accumulation of bilirubin in the renal papilla is associated with a progressive impairment of the capacity of the renal medullary structures to form and maintain the necessary hypertonicity of interstitial fluid. Such an interpretation would explain the failure in older homozygous animals for maximal reabsorption of solute-free water during thirsting. The accumulation of bilirubin in the kidney of homozygous animals is presumably dependent upon the postnatal retention of bilirubin and/or related to the change in the animals' diet from maternal milk to laboratory chow.

It has been previously postulated from in vitro studies $[18,19]$ that the accumulation of bilirubin in the renal medulla was related to the high ionic strength of the medullary fluid. By this mechanism, the protein-bound bilirubin circulating through the vasa recta is exposed to media of high ionic strength which increases the dissociation of bilirubin from the plasma protein and permits its escape to the extravascular medullary structures. The medullary solute content, and therefore ionic strength, of the kidneys in young animals is known to be lower than that of older animals of the same species [6] and could account for the lower concentrations of bilirubin in the medulla of weanling animals. Protection from bilirubin accumulation would also occur if the diet of the suckling ainmal contained minimal solute for excretion in the available water for urine formation. Under such dietary circumstances, the renal medullary fluid would not be as hypertonic as it is during antidiuresis.

An unexpected finding was the close correlation between the concentrations of sodium and urea in the medulla in the homozygous animals; this was not found in the heterozygous animals. Reexamination of the previously reported studies in adult animals [18] revealed the same correlation between the concentrations of sodium and urea in the medulla in the jaundiced rats and an absence of such a correlation in the medullary solute composition of the pair-fed control animals. The combined data from the previously studied adult homozygous animals and the presently reported weanling jaundiced rats are shown in figure 1. The regression line indicates that concentrations of urea in the papillae were related to the simultaneous concentrations of sodium in a 2:1 molar ratio within the range of observed values.

A number of studies have indicated that the movement of urea in the mammalian kidney may occur by two distinct mechanisms. The first, elucidated by BERLINER and others, is related to the passive diffusion of urea from the collecting duct to the peritubular fluid along a concentration gradient $[1,7,12,13,16]$. During antidiuresis, urine in the collecting duct undergoes concentration by the osmotic movement of water across the duct epithelium into the hypertonic interstitium. The hypertonicity of the medullary interstitium is created by the active reabsorption and counter current recirculation of sodium from the ascending limb of the loop of Henle [10]. As water leaves urine in the collecting duct, the concentration of urea increases and urea can diffuse passively into the adjacent medullary interstitium consistent with its concentration gradient across the duct epithelium. This passive diffusion of urea is enhanced by antidiuretic hormone [7, 17]. Consequently, one might anticipate a correlation between the concentrations of sodium and urea in the renal medulla.

It has been suggested that the other mechanism for urea transport by the kidney is an active process $[2,4,5$, $9,13,14,20,22]$ whereby urea can be concentrated within the medullary interstitium even though its concentration is lower within the lumen than in the peritubular fluid of the collecting duct. Bray and Preston [2], as well as Truniger and Schmidt-NieLSEN [20], found urea concentrations lower in urine than in the medullary tissue slices of the kidney from proteindeficient rats. LASSITER et al. [14] have subșequently shown by micropuncture sampling techniques that the concentration of urea within the vasa recta was greater than it was in the adjacent collecting duct. By this active transport mechanism, urea content of the medulla may vary independently of sodium reabsorption.

The present results are consistent with an interpretation that the mechanism for tubular transport of urea which is independent of sodium reabsorption was impaired in the jaundiced Gunn rat and is the earliest manifestation of bilirubin nephropathy. Only later, when the medullary concentration of bilirubin increases, does sodium reabsorption become impaired; then the urinary concentrating defect is apparent.

Although the animals were litter-mates of comparable weight, they were not pair fed and their urinary excretions were not actually measured. The interpretation, therefore, suggested for the urea results must remain as conjecture until more definitive data are available.

\section{Summary}

The response to thirsting of weanling jaundiced ( $\mathrm{jj}$ ) and non-jaundiced (jJ) Gunn strain rats was compared. In contrast to adult $(\mathrm{jj})$ rats, it was found that the weanling (jj) rat was able to generate hypertonic concentrations of sodium and urea in the renal medulla comparable to that found in the non-jaundiced littermate. The calculated milli-osmolalities in tissue were 1563 and $1632 / \mathrm{kg}$ of medullary tissue water respectively. Consequently, the polyuria characteristic of older ani- 
mals would not be expected in weanling animals. Only two of the 12 jaundiced weanling animals exhibited impairment of water conservation qualitatively similar to that uniformly seen in mature (jj) animals.

It was found that the medullary concentration of bilirubin in the weanling $\mathrm{jj}$ rat was $0.05 \mu \mathrm{g} / \mathrm{mg}$ wet weight. This concentration is only $5 \%$ of the value observed in mature animals despite higher concentrations of bilirubin in serum in the weanling rats.

In both the weanling and adult jaundiced rats, there was a significant correlation between the concentrations of sodium and urea in the medulla which was not observed in control animals. These observations suggested that the earliest lesion of bilirubin nephropathy may be an interference with the capacity of the medullary structures to control urea movement independently of sodium transport.

\section{References and Notes}

1. Berliner, R.W.; Levinsky, N.T.; Davidson, D. G. and EDEN, M.: Dilution and concentration of the urine and the action of antidiuretic hormone. Amer.J. Med. 24: 730 (1958).

2. BRAY, G. A. and Preston, A.S.: Effect of urea on urine concentration in the rat. J. clin. Invest. 40: 1952 (1961).

3. Carbone, J.V. and Grodsky, G.M.: Constitutional non-hemolytic hyperbilirubinemia in the rat. Proc. Soc. exp. Biol. (N.Y) 94: 461 (1957).

4. CRawford, J. D.; Doyle, A.P. and Probst, J. H.: Service of urea in renal water conservation. Amer. J. Physiol. 196: 545 (1959).

5. Finn, A.T. and Welt, L. G.: Urea excretion in the potassium-deficient rat. Proc. Soc. exp. Biol. (N.Y.) 124: 724 (1967).

6. Forrest, J.N., Jr. and Stainer, M.W.: Kidney composition and renal concentration ability in young rabbits. J. Physiol., Lond. 187: 1 (1966).

7. Gardner, K.D., Jr. and Maffly, R.H.: An invitro demonstration of increased collecting tubular permeability to urea in the presence of vasopressin. J. clin. Invest. 43: 1968 (1964).

8. Gotrschalk, C.W.: Osmotic concentration and dilution of urine. Amer.J.Med. 36: 670 (1964).

9. Halpern, R. M. ; Halpern, B. G. and Hall, V. E. : The relation of the kidney to body growth and to the utilization of protein and urea. Nephron 1: 203 (1964).

10. Jamison, R.T.; Bennett, C.M. and Berliner, R.W.: Counter-current multiplication by the thin loops of Henle. Amer. J. Physiol. 212: 357 (1967).

11. Johnson, L.; Sarmiento, F.; Blanc, W.A. and DAY, R. : Kernicterus in rats with an inherited de- ficiency of glucuronyl transferase. Amer.J. Dis. Child. 97: 591 (1959).

12. Lassiter, W.E.; GotTschalk, G.W. and Mylle, M.: Micropuncture study of net transtubular movement of water and urea in nondiuretic mammalian kidney. Amer.J. Physiol. 200: 1139 (1961).

13. Lassiter, W.E.; Mylle, M. and Gottschalk, G.W.: Net transtubular movement of water and urea in saline diuresis. Amer.J.Physiol. 206: 669 (1964).

14. Lassiter, W.E.; Mylle, M. and Gottschalk, C.W.: Micropuncture study of urea transport in rat renal medulla. Amer. J.Physiol. 210: 965 (1966).

15. LATHE, G.H. and WALKer, M. : An enzyme defect in human neonatal jaundice and in Gunn's strain of jaundiced rats. Biochem.J. 67: 9P (1957).

16. Levinsky, N.G.; Berliner, R.W. and Preston, A.S.: The role of urea in the urine concentrating mechanism. J.clin. Invest. 38: 741 (1959).

17. Maffly, R.H.; Hays, R.M.; Lamdin, E. and LEAF, A.: The effect of neurohypophyseal hormones on the permeability of the toad bladder to urea. J. clin. Invest. 39: 630 (1960).

18. Odell, G.B.; NatzschKa, J.G. and Srorey, G.N.B.: Bilirubin nephropathy in the Gunn strain of rat. Amer. J. Physiol. 212: 931 (1967).

19. Odell, G.B.: The distribution of bilirubin between albumin and mitochondria. J.Pediat. 68: 164 (1966).

20. TRUniger, B. and Schmidt-Nielsen, B. : Intrarenal distribution of urea and related compounds: Effects of nitrogen intake. Amer.J. Physiol. 207: 971 (1964).

21. Schmid, R.; Axelrod, J.; Hammaker, T. and SwARM, R.T.: Congenital jaundice in rats, due to a defect in glucuronide formation. J.clin. Invest. 37: 1123 (1958).

22. SGHMidt-Nielsen, B.: Urea excretion in mammals. Physiol. Rev. 38: 139 (1958).

23. Ullrich, K.J.; Kramer, K. and Boylan, J.W.: Present knowledge of the counter-current system in the mammalian kidney; in: Heart, kidney and electrolytes (ed. C.K.FriedrerG), p. 1 (Grune and Stratton, New York 1962).

24. WIRZ, H.: The location of antidiuretic action in the mammalian kidney; in: The neurohypophysis (ed. H.Heller), p. 157 (Academic Press, New York 1957).

25. This investigation was supported by Research Grant HD-02268 from the National Institute of Child Health and Human Development, USPHS.

26. Requests for reprints should be addressed to: Gerard B. Odelt, M.D., Department of Pediatrics, The Johns Hopkins Hospital, Baltimore, Md. 21205 (USA). 